\title{
Misinterpretation or Underestimation of the Appearance, Location, or Size of Non-bleeding Visible Vessels (Forrest Class Ila) as a Cause of Hemostasis Failure
}

\author{
Hidehiro Kamezaki ${ }^{1,}{ }^{*}$, Dai Sakamoto ${ }^{1}$, Daiki Okamura ${ }^{2}$, Koji Nakagawa ${ }^{2}$, Naoya Kato ${ }^{3}$
}

1. Department of Gastroenterology, Eastern Chiba Medical Center, 3-6-2, Okayamadai, Togane, Japan; E-Mails: ugn29814@yahoo.co.jp (HK), daitai23xyz@yahoo.co.jp (DS)

2. Department of Surgery, Eastern Chiba Medical Center, 3-6-2, Okayamadai, Togane, Japan; EMails: okamura.chiba@gmail.com (DO), nakagawa-k@chiba-u.jp (KN)

3. Department of Gastroenterology, Chiba University, Graduate School of Medicine, 1-8-1, Inohana, Chuo-ku, Chiba, Japan; E-mail: kato.naoya@chiba-u.jp (NK)

* Correspondence: Hidehiro Kamezaki; E-Mail: ugnn29814@yahoo.co.jp

Academic Editor(s): Tatsuo Kanda

OBM Hepatology and Gastroenterology

2018, volume 2, issue 1

doi:10.21926/obm.hg.1801006
Received: December 10, 2017

Accepted: February 27, 2018

Published: March 15, 2018

\begin{abstract}
(1) Background: Endoscopy has become the primary diagnostic and therapeutic technique for non-variceal upper gastrointestinal bleeding. Despite advances in therapeutic methods and instrumentation, endoscopic hemostatic failure occurs in $10 \%$ of patients. In this study, we aimed to analyze the endoscopic findings in patients with failed hemostasis and to elucidate strategies for endoscopists and gastroenterologists to facilitate improved treatment outcomes.
\end{abstract}

(2) Methods: A total of 128 patients received hemostatic treatment for non-variceal upper gastrointestinal bleeding. Endoscopic findings in three patients with failed hemostasis after the initial and secondary endoscopies were analyzed.

(3) Results: Hemostasis failure occurred in three cases (2.3\%). All three cases involved patients with gastric ulcer and were categorized as Forrest class lla presenting with a non-

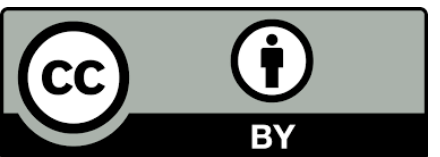

(C) 2018 by the author. This is an open access article distributed under the conditions of the Creative Commons by Attribution License, which permits unrestricted use, distribution, and reproduction in any medium or format, provided the original work is correctly cited. 
bleeding visible vessel in endoscopic findings. Misinterpretation or underestimation of the appearance, location, or size of the vessel resulted in hemostasis failure.

(4) Conclusions: Our findings demonstrate that identification of a non-bleeding visible vessels and assessment of the risk of re-bleeding in such vessels is often difficult. Detailed examination of the ulcer floor with awareness of the possibility of a non-bleeding visible vessel will lead to improved hemostatic treatment outcomes. The decision regarding hemostatic treatment of a visible vessel with a diameter exceeding $2 \mathrm{~mm}$ should be made cautiously, and treatment should be followed by an appropriate period of fasting prior to endoscopic confirmation of successful hemostasis.

\section{Keywords}

Endoscopic hemostasis; Gastrointestinal endoscopy; Non-bleeding visible vessel; Peptic ulcer hemorrhage; Non-variceal upper gastrointestinal bleeding

\section{Introduction}

Acute upper gastrointestinal bleeding (UGIB) is a potentially life-threatening abdominal emergency that remains a common cause of hospitalization. UGIB is defined as bleeding derived from a source proximal to the ligament of Treitz. The most common non-variceal bleeding etiologies include gastroduodenal peptic ulcer (20\%-50\%), gastroduodenal erosions (8\%-15\%), Mallory-Weiss tears (8\%-15\%), erosive esophagitis (5\%-15\%), and arteriovenous malformations/gastric antral vascular ectasia (GAVE; 5\%) [1]. Approximately $50 \%$ of non-variceal UGIB is caused by peptic ulcers [2, 3], which occur mainly in the stomach (gastric ulcer) or proximal duodenum (duodenal ulcer). Duodenal ulcer bleeding appears more frequently than bleeding from gastric ulcers [4]. Helicobacter pylori infection, nonsteroidal anti-inflammatory drugs (NSAIDs), and acetylsalicylic acid are the main risk factors for UGIB [5], which occurs with an incidence ranging from 48 to 160 cases per 100,000 adults annually and results in mortality in $10 \%$ to $14 \%$ of cases [6]. Although UGIB is more common in men than in women, the mortality rates are the same. In Japan $[7,8]$, the rate of $H$. pylori infection has declined in young people; however, mortality rates associated with UGIB remain high due to an increased proportion of elderly patients with accompanying comorbidities and more frequent use of NSAIDs and anti-thrombotic drugs. In patients aged less than 60 years with no relevant comorbidities, the mortality rate is close to zero [9].

Endoscopy has become the primary diagnostic and treatment technique for non-variceal UGIB. The utility of endoscopic hemostasis in the treatment of hemorrhagic gastroduodenal ulcers has been demonstrated in a meta-analysis reported by Marmo et al. [10]. Endoscopic hemostasis is believed to significantly reduce the incidence of recurrent and continuous bleeding, as well as the need for emergency surgery. In another meta-analysis, Barkun et al. found that endoscopic hemostasis significantly reduced the mortality rate [11].

Several new endoscopic hemostasis technologies have been developed over the years. Selfexpanding metal stents, hemostatic forceps, hemostatic powders, and over-the-scope clips are currently used in endoscopic hemostasis treatment [12]. Despite ongoing improvements in 
endoscopic and pharmacologic therapies, bleeding continues or recurs in more than $10 \%$ of patients after initial endoscopic hemostasis treatment [13]. However, repeated endoscopic therapy usually has a favorable effect in cases of re-bleeding. Large ulcer size and posterior duodenal and lesser gastric curvature ulcers have been suggested as independent predictors of rebleeding [14]. Obscured endoscopic appearance, especially in the case of a non-bleeding visible vessel (Forrest grade Ila), can also result in the failure of hemostasis.

In this study, we aimed to analyze endoscopic findings in patients with endoscopic hemostasis failure and to provide observations that might aid gastroenterologists and endoscopists in improving the prevention of re-bleeding and reducing the requirement for surgical intervention.

\section{Ethics Statement}

This retrospective study was approved by the Ethics Committee of the Eastern Chiba Medical Center in Chiba, Japan (Approval number: 49). The study conformed to the ethical guidelines of the Declaration of Helsinki. Written informed consent was acquired from all patients before emergency endoscopic examination. Registration for this study has been carried out on the hospital website.

\section{Materials and Methods}

Eastern Chiba Medical Center was designated as an emergency hospital in April 2014. Among the 3,547 cases of upper gastrointestinal endoscopy performed in our department between April 2014 and March 2017, 324 (9.1\%) procedures were performed for therapeutic purposes. Another 128 (3.6\%) were performed as a hemostatic treatment for acute non-variceal UGIB, including 85 cases of gastroduodenal ulcers and 15 cases of Mallory-Weiss syndrome. The characteristics of these patients are shown in Table 1. Cases of failed endoscopic hemostasis were defined as patients in whom hemostasis could not be achieved by initial or second endoscopic treatment (after re-bleeding). These included: (1) patients whose treatment had to be converted to surgery, (2) patients who ultimately required transarterial embolization, and (3) patients whose condition eventually led to their death. Among the 128 patients, there were three cases (2.3\%) of failed endoscopic hemostasis.

\subsection{Endoscopic Hemostasis Procedure}

Patients were subjected to a varying degree of conscious sedation depending on their condition. The Olympus flexible EVIS EXERA endoscope was used. The hemorrhage was treated using mainly mechanical therapy with the deployment of hemoclips (non-reopening, rotary Olympus clips). A solution of $5 \%$ hypertonic saline epinephrine or ethanol was injected simultaneously in some cases. Argon plasma coagulation (APC) or endoscopic mucosal resection (EMR) was used in some other cases. 
Table 1 Characteristics of the 128 cases of hemostatic treatment performed in patients with non-variceal upper gastrointestinal bleeding

\begin{tabular}{|c|c|c|c|c|c|c|c|c|}
\hline & \multirow{2}{*}{ Number } & \multirow{2}{*}{ Male } & \multirow{2}{*}{ Female } & \multicolumn{3}{|c|}{ Age (years) } & \multirow{2}{*}{ Shock } & \multirow{2}{*}{$\begin{array}{l}\text { Liver } \\
\text { cirrhosis }\end{array}$} \\
\hline & & & & Median & Min. & Max. & & \\
\hline $\begin{array}{l}\text { Gastroduoden } \\
\text { al ulcer }\end{array}$ & 85 & 68 & 17 & 67 & 29 & 91 & $\begin{array}{c}42 \\
(49.4 \%)\end{array}$ & $\begin{array}{c}1(1.2 \%) \\
C\end{array}$ \\
\hline $\begin{array}{l}\text { Mallory-Weiss } \\
\text { syndrome }\end{array}$ & 15 & 11 & 4 & 72 & 44 & 93 & $6(40.0 \%)$ & $\begin{array}{c}2 \\
(13.3 \%) \\
\text { A/B } \\
\end{array}$ \\
\hline Gastric polyp & 6 & 4 & 2 & 84 & 64 & 91 & $3(50.0 \%)$ & $\begin{array}{c}1 \\
(16.7 \%) \\
\text { B }\end{array}$ \\
\hline $\begin{array}{c}\text { Gastric } \\
\text { angioectasia }\end{array}$ & 5 & 4 & 1 & 76 & 65 & 83 & $0(0 \%)$ & $0(0 \%)$ \\
\hline $\begin{array}{l}\text { latrogenic } \\
\text { disease }\end{array}$ & 4 & 4 & 0 & 75.5 & 71 & 79 & $1(25.0 \%)$ & $0(0 \%)$ \\
\hline $\begin{array}{c}\text { Gastric antral } \\
\text { vascular } \\
\text { ectasia }\end{array}$ & 4 & 1 & 3 & 73 & 46 & 84 & $0(0 \%)$ & $\begin{array}{l}4(100 \%) \\
B / B / C / C\end{array}$ \\
\hline $\begin{array}{c}\text { Reflux } \\
\text { esophagitis }\end{array}$ & 3 & 3 & 0 & 81 & 62 & 82 & $1(33.3 \%)$ & $\begin{array}{c}0 \\
(0 \%) \\
\end{array}$ \\
\hline Gastric cancer & 3 & 3 & 0 & 68 & 66 & 89 & 2 (66.7\%) & $0(0 \%)$ \\
\hline $\begin{array}{c}\text { Acute } \\
\text { necrotizing } \\
\text { esophagitis }\end{array}$ & 1 & 1 & 0 & 51 & 51 & 51 & $1(100 \%)$ & $0(0 \%)$ \\
\hline $\begin{array}{c}\text { Gastric } \\
\text { anisakiasis }\end{array}$ & 1 & 1 & 0 & 66 & 66 & 66 & $0(0 \%)$ & $0(0 \%)$ \\
\hline $\begin{array}{c}\text { Gastric } \\
\text { Iymphoma }\end{array}$ & 1 & 1 & 0 & 58 & 58 & 58 & $0(0 \%)$ & $0(0 \%)$ \\
\hline Total & 128 & 101 & 27 & 70 & 29 & 93 & $\begin{array}{c}56 \\
(43.8 \%)\end{array}$ & $8(6.3 \%)$ \\
\hline
\end{tabular}

Shock, systolic blood pressure $<90 \mathrm{mmHg}$ and / or shock index (pulse rate/systolic blood pressure) >1.0; A, Child-Pugh classification grade A; B, Child-Pugh classification grade B; C, Child-Pugh classification grade $C$

\section{Results}

Table 2 shows the clinical and pathological characteristics of the patients with failed endoscopic hemostasis. Their treatment was immediately changed to gastrectomy; as a result, all three patients survived. In all three cases, the patients had gastric ulcers, and there were no specific clinical features to differentiate these patients from the rest of the UGIB population in whom 
endoscopic hemostasis was successful. Detailed analysis of the endoscopic findings was performed for each patient.

Table 2 Characteristics of the patients with failed endoscopic hemostasis.

\begin{tabular}{|c|c|c|c|}
\hline Case & 1 & 2 & 3 \\
\hline Age (years) & 43 & 66 & 42 \\
\hline Sex & Male & Female & Male \\
\hline Major clinical symptoms & Hematemesis & Hematemesis & Hematemesis \\
\hline Diagnosis & Gastric ulcer & Gastric ulcer & Gastric ulcer \\
\hline Locations & $\begin{array}{l}\text { Lesser curvature, } \\
\text { gastric angle }\end{array}$ & $\begin{array}{c}\text { Lesser curvature, } \\
\text { gastric angle }\end{array}$ & $\begin{array}{l}\text { Posterior wall, } \\
\text { gastric corpus }\end{array}$ \\
\hline Accompanying diseases & None & None & None \\
\hline Anti-thrombotic drugs & - & - & - \\
\hline NSAIDs & - & - & + \\
\hline Thrombopenia & - & - & - \\
\hline Coagulation disorder & - & - & - \\
\hline Helicobacter pylori & - & - & + \\
\hline $\begin{array}{c}\text { Professional experience of } \\
\text { doctor (years) }\end{array}$ & 10 & 12 & 11 \\
\hline
\end{tabular}

Abbreviation: NSAIDS, nonsteroidal anti-inflammatory drugs

Endoscopic images of the first patient are shown in Figure 1. The patient presented with hematemesis; however, his vital signs were stable. Endoscopic evaluation performed two days after admission revealed a gastric ulcer, and the exposed vessel (a non-bleeding visible vessel according to Forrest classification-class Ila) was treated mechanically with the deployment of hemoclips. Endoscopic observation conducted the next day showed that the clip had dislodged and that the exposed blood vessel was flattened, stabilized, and exhibiting a uniform white coating consisting mainly of a thick layer of necrotized mucosal tissue (Fig. 1a). Following endoscopic observation the next day, oral feeding was resumed. However, the endoscopic image of the treated exposed vessel proved misleading, and re-bleeding occurred within 24 hours after resumption of oral feeding. Endoscopic hemostatic treatment was repeated, but hemostasis was not achieved (Fig. 1b). 

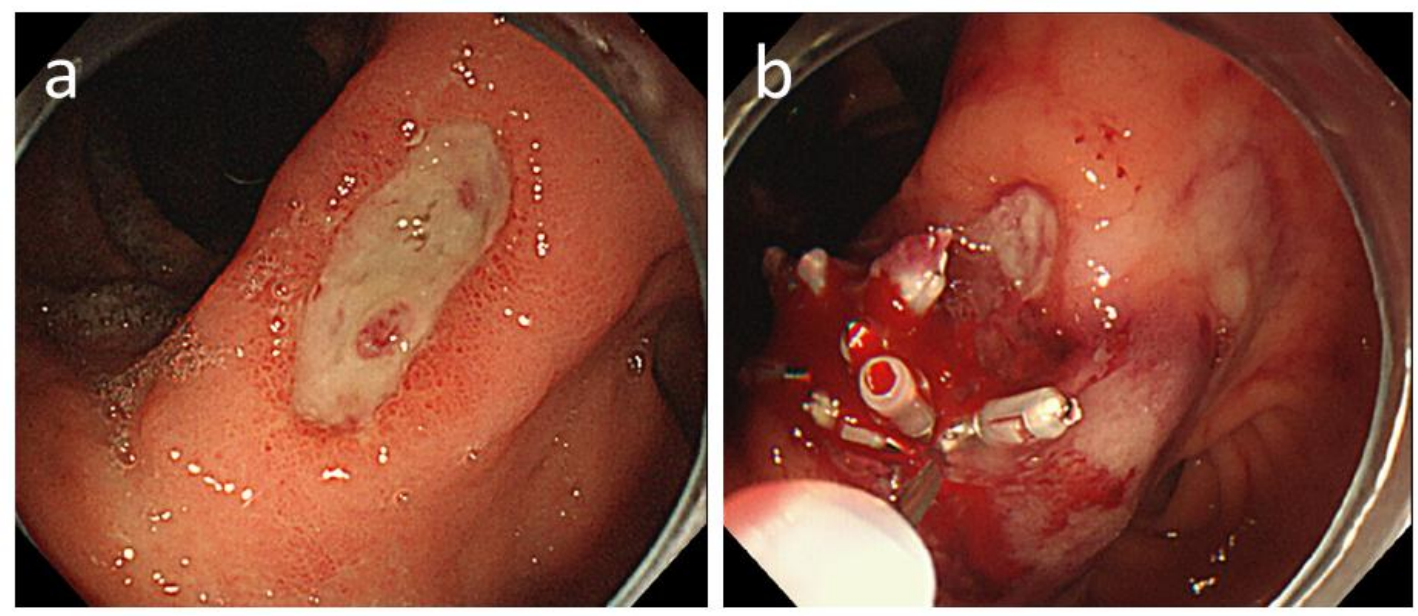

Figure 1 Patient 1: first and second hemostatic endoscopy. a: Initial endoscopic hemostasis. The exposed blood vessel was flattened, stabilized, and covered with a uniform white coating, which was shown microscopically to be composed mainly of a thick layer of necrotized mucosal tissue. b: The second endoscopic hemostatic treatment of the recurrent bleeding after the resumption of oral feeding; hemostasis was not achieved.

Endoscopic images of the second patient are shown in Figure 2. The patient presented with hematemesis and her vital signs were unstable. Endoscopic evaluation performed within three hours after admission revealed a gastric ulcer, and the exposed blood vessel was treated by the deployment of hemoclips. Two days after endoscopic hemostasis, re-bleeding occurred and endoscopic evaluations showed a hemorrhage from another point in the ulcer floor (Fig. 2a and $2 \mathrm{~b}$; arrows). Although the patient received endoscopic hemostatic treatment, hemostasis was not achieved (Fig. 2b). This failure suggested that the presence of multiple exposed blood vessels went unnoticed during the initial examination, probably owing to insufficient detachment and removal of blood clots.
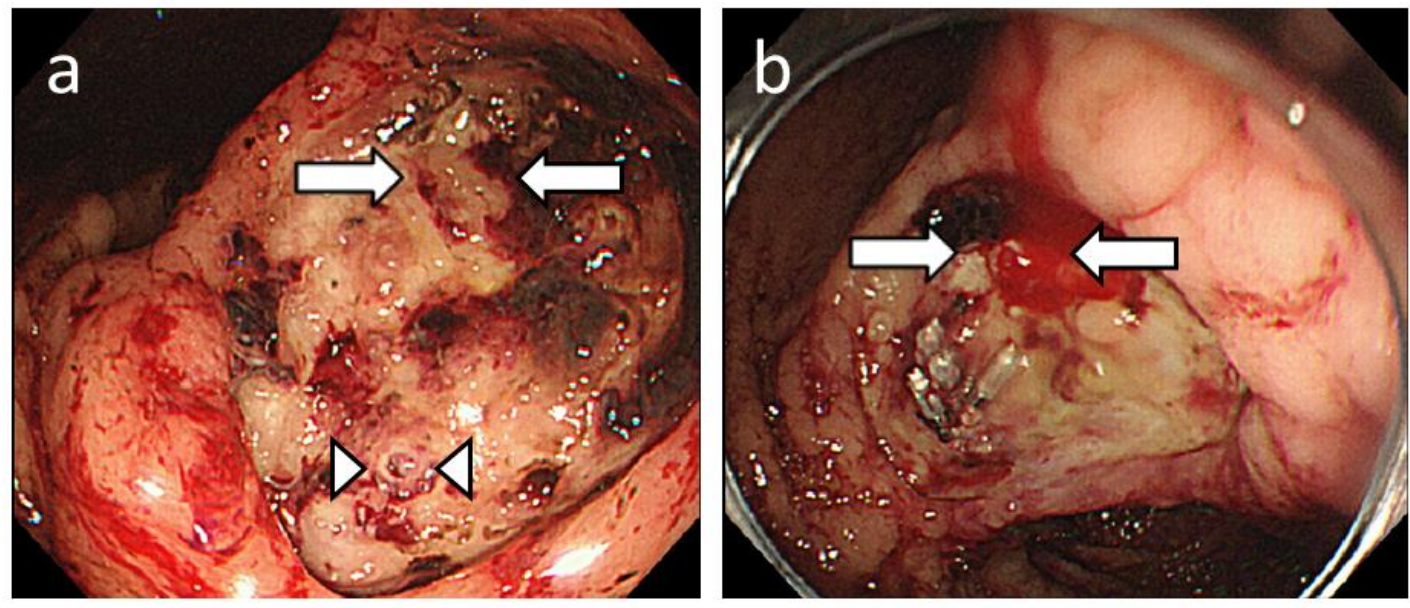

Figure 2 Patient 2: first and second hemostatic endoscopy. a: Initial endoscopic hemostasis. The exposed blood vessel (arrowheads) was treated by the deployment of hemoclips. b: The second endoscopic hemostatic treatment of the recurrent bleeding from a different point on the ulcer floor (arrows); hemostasis was not achieved. 
Endoscopic images of the third patient are shown in Figure 3. The patient presented with hematemesis; however, his vital signs were stable. Endoscopic evaluation performed the day after admission revealed the presence of a gastric ulcer. Although the bleeding was shown to have stopped spontaneously, the ulcer floor was covered with a white coating, and the exposed blood vessel was no longer visible (Fig. 3a). Based on these observations, oral feeding was resumed the next day. One day later, the re-bleeding occurred and prompted a second endoscopy. After a local injection of ethanol, endoscopic observation revealed the presence of a thick, white blood vessel (Fig. 3b). The attempt at hemostasis with hemoclips failed. The blood vessel was extremely large, which may account for the lack of recognition of the ulcer floor irregularities as a blood vessel during the initial endoscopy.
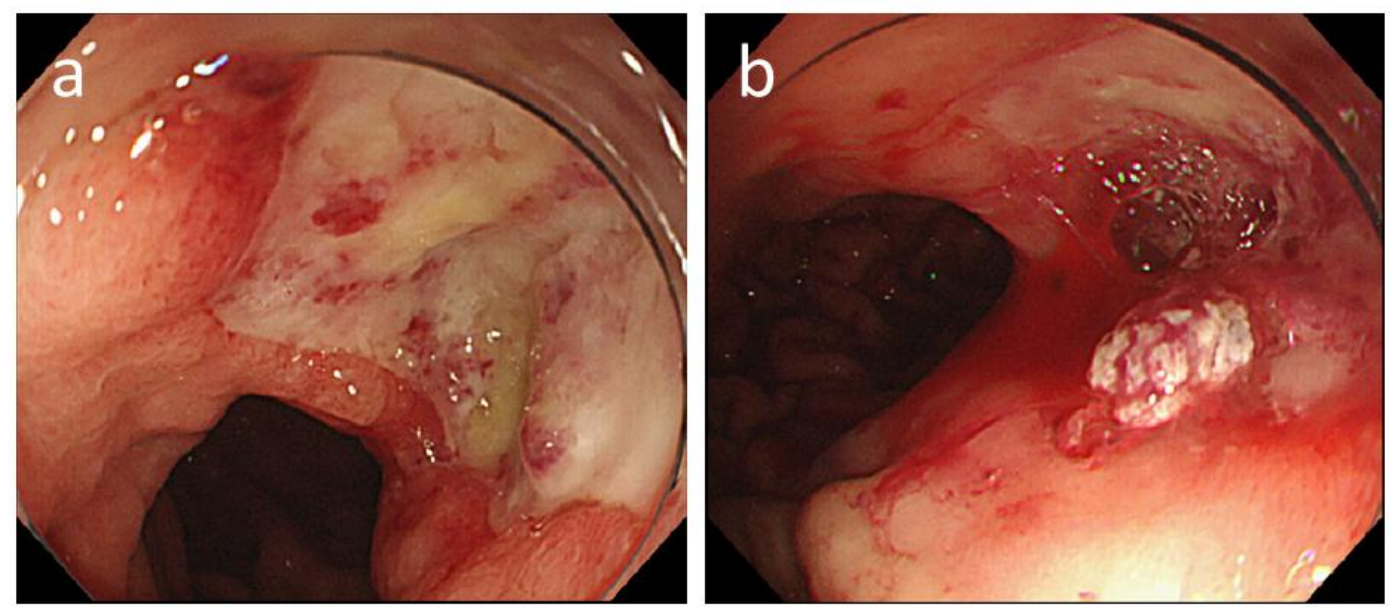

Figure 3 Patient 3: first and second hemostatic endoscopy. a: Initial endoscopic hemostasis. The ulcer floor was covered with a white coating. The non-bleeding blood vessel was not visible. $b$ : The second endoscopic hemostatic treatment of the recurrent bleeding after the resumption of oral feeding. After a local injection of ethanol, a thick white blood vessel was revealed. Endoscopic hemostatic treatment was performed, but hemostasis was not achieved.

In all three cases, either the presence of a visible blood vessel was overlooked or underestimated, which subsequently influenced the clinical course.

\section{Discussion}

Despite advancements in endoscopic hemostasis techniques, recurrent bleeding occurs in $10 \%$ to $20 \%$ of cases.

Forrest et al. were the first to classify the stigmata of hemorrhage in peptic ulcers [15]. The Forrest classification has shown a higher specificity and positive predictive value for re-bleeding and death when compared to the other four scoring systems that have been evaluated [Rockall score, Cedars-Sinai Medical Center Predictive Index (CSMCPI), Glasgow-Blatchford Bleeding score (GBS), and Baylor Bleeding Score (BBS)] [16]. The Forrest classification divides ulcers into six different categories according to the endoscopic findings. High-risk lesions include those characterized by spurting hemorrhages (Forrest la), oozing hemorrhages (Forrest lb), non-bleeding visible vessels (Forrest Ila), or adherent clots (Forrest Ilb). Low-risk lesions include hematin on the 
ulcer base (Forrest IIc) and a clean ulcer base (Forrest III). According to the American College of Gastroenterology guidelines, endoscopic hemostasis should be performed on actively bleeding blood vessels (Forrest class I) and non-bleeding visible blood vessels (Forrest class Ila). For ulcers with adherent clots (Forrest $\mathrm{llb}$ ), clot removal should be attempted by vigorous irrigation, and patients should be treated according to the underlying lesion [17].

A review of the endoscopic findings in each patient described here revealed that, in all the cases, the failure of endoscopic hemostasis was due to overlooking or underestimating nonbleeding visible blood vessels (Forrest class Ila). The risk of further bleeding of a non-bleeding blood vessel (defined as "a pigmented protuberance in the ulcer"), ranges from $40 \%$ to 50\% [18, 19]. Due to the high risk of recurrent bleeding, endoscopists should recognize the potential significance non-bleeding blood vessels, which should be monitored closely.

The appearance of a white color in a non-bleeding visible vessel is one factor that has been associated with a higher risk of further bleeding. Other factors include a peripherally located vessel within an ulcer floor and the size of the vessel [20]. The three cases of failed hemostasis described here exemplify these high-risk lesions. In the first patient, white coating of the flattened vessel was misinterpreted as successful hemostasis, and oral feeding was resumed prematurely. In the second patient, an additional non-bleeding vessel at the ulcer periphery was overlooked. Rebleeding occurred occurred in both cases.

The exposed vessel of the third patient had a vascular diameter that greatly exceeded $2 \mathrm{~mm}$. Ishikawa et al. previously reported that an exposed blood vessel with a diameter of $2 \mathrm{~mm}$ or more was a risk factor for recurrent bleeding [21]. According to Lin et al., the rate of recurrent bleeding is directly correlated with the size of a non-bleeding visible vessel [19]. The identification of very large visible vessel by endoscopy, as in Case 3, should alert the endoscopist to the risk of unsuccessful hemostasis, and raise the question of whether the treatment is advisable.

Our study suggests that, in cases of spontaneous hemostasis with no visible bleeding, irrigation of the ulcer should be performed by the endoscopist to explore the possibility of a non-bleeding visible vessel. Raised protuberances within the ulcer bed should be evaluated to determine whether they are non-bleeding visible vessels. Such precautions will lead to the improvement of the treatment outcome. Magnification endoscopy might improve the characterization of the vessel in terms of its size, color, and location within the ulcer bed, although its clinical significance remains debatable [22]. In addition, a Doppler probe is a useful indicator of successful hemostasis $[23,24]$.

The timing of the resumption of oral feeding after endoscopic hemostasis treatment in patients with UGIB has not been sufficiently investigated. Murata's group suggested that fasting should be continued for three days after hemostasis [25]; however, more recent findings suggest that in interval of 48-hours or less after endoscopic hemostasis is appropriate [26, 27]. Our study demonstrated that oral feeding of the third patient with a large non-bleeding blood vessel and a high risk of re-bleeding should have been delayed. In this case, the timing of the resumption of oral feeding should have been dictated by repetitive confirmatory endoscopy.

\section{Conclusions}

In conclusion, Forrest class la, Ib, and Ila UGIB all show a high risk of recurrent bleeding after endoscopic hemostasis. Our findings demonstrate the challenges associated with identification 
non-bleeding visible vessels (Forrest class $\mathrm{Ila}$ ) and assessing the potential risk of re-bleeding in these vessels. The endoscopy should be performed cautiously and with consideration of the possibility of re-bleeding. Moreover, detailed observation of the ulcer floor with specific vigilance for non-bleeding visible vessels will lead to more successful hemostatic treatment. The necessity for the hemostatic treatment of visible vessels with a diameter exceeding $2 \mathrm{~mm}$ should be rigorously assessed, and treatment should be followed by an appropriate period of fasting prior to endoscopic confirmation of successful hemostasis.

\section{Acknowledgments}

Editorial support, in the form of medical writing based on authors' detailed directions, collating author comments, copyediting, fact-checking, and referencing, was provided by Cactus Communications.

\section{Author Contributions}

Conception and study design: Kamezaki; Data collection: Kamezaki, Sakamoto; Analysis and interpretation: Kamezaki, Okamura, Nakagawa; Writing of manuscript: Kamezaki; Critical review of manuscript: Kato. All authors have read and approved the final version of the manuscript.

\section{Funding}

None.

\section{Competing Interests}

The authors have declared that no competing interests exist.

\section{References}

1. Gilbert DA. Epidemiology of upper gastrointestinal bleeding. Gastrointest Endosc. 1990; 36: S8-13.

2. Lau JY, Sung J, Hill C, Henderson C, Howden CW, Metz DC. Systematic review of the epidemiology of complicated peptic ulcer disease: incidence, recurrence, risk factors and mortality. Digestion. 2011; 84: 102-113.

3. Sung JJ, Kuipers EJ, El-Serag HB. Systematic review: the global incidence and prevalence of peptic ulcer disease. Aliment Pharmacol Ther. 2009; 29: 938-946.

4. Biecker E. Diagnosis and therapy of non-variceal upper gastrointestinal bleeding. World J Gastrointest Pharmacol Ther. 2015; 6: 172-182.

5. Loperfido S, Baldo V, Piovesana E, Bellina L, Rossi K, Groppo M, et al. Changing trends in acute upper-GI bleeding: a population-based study. Gastrointest Endosc. 2009; 70: 212-224.

6. Quan S, Frolkis A, Milne K, Molodecky N, Yang H, Dixon E, et al. Upper-gastrointestinal bleeding secondary to peptic ulcer disease: incidence and outcomes. World J Gastroenterol. 2014; 20: 17568-17577. 
7. Kawai T, Yamamoto K, Fukuzawa M, Yamagishi T, Yagi K, Fukuzawa M, et al. Helicobacter pylori infection and reflux esophagitis in young and middle-aged Japanese subjects. J Gastroenterol Hepatol. 2010; 25 Suppl 1: S80-85.

8. Pellicano R, Ribaldone DG, Fagoonee S, Astegiano M, Saracco GM, Megraud F. A 2016 panorama of Helicobacter pylori infection: key messages for clinicians. Panminerva Med. 2016; 58: 304-317.

9. Kawaguchi K, Kurumi H, Takeda Y, Yashima K, Isomoto H. Management for non-variceal upper gastrointestinal bleeding in elderly patients: the experience of a tertiary university hospital. Ann Transl Med. 2017; 5: 181.

10. Marmo R, Rotondano G, Piscopo R, Bianco MA, D'Angella R, Cipolletta L. Dual therapy versus monotherapy in the endoscopic treatment of high-risk bleeding ulcers: a meta-analysis of controlled trials. Am J Gastroenterol. 2007; 102: 279-289; quiz 469.

11. Barkun AN, Martel M, Toubouti Y, Rahme E, Bardou M. Endoscopic hemostasis in peptic ulcer bleeding for patients with high-risk lesions: a series of meta-analyses. Gastrointest Endosc. 2009; 69: 786-799.

12. Jacques J, Legros R, Chaussade S, Sautereau D. Endoscopic haemostasis: an overview of procedures and clinical scenarios. Dig Liver Dis. 2014; 46: 766-776.

13. Roy A, Kim M, Hawes R, Varadarajulu S. The clinical and cost implications of failed endoscopic hemostasis in gastroduodenal ulcer bleeding. United European Gastroenterol J. 2017; 5: 359364.

14. Elmunzer BJ, Young SD, Inadomi JM, Schoenfeld P, Laine L. Systematic review of the predictors of recurrent hemorrhage after endoscopic hemostatic therapy for bleeding peptic ulcers. Am J Gastroenterol. 2008; 103: 2625-2632; quiz 2633.

15. Forrest JA, Finlayson ND, Shearman DJ. Endoscopy in gastrointestinal bleeding. Lancet. 1974; 2: 394-397.

16. Monteiro S, Goncalves TC, Magalhaes J, Cotter J. Upper gastrointestinal bleeding risk scores: Who, when and why? World J Gastrointest Pathophysiol. 2016; 7: 86-96.

17. Laine L, Jensen DM. Management of patients with ulcer bleeding. Am J Gastroenterol. 2012; 107: 345-360; quiz 361.

18. Liu JJ, Saltzman JR. Closer examination of the nonbleeding visible vessel. Gastrointest Endosc. 2010; 72: 419-421.

19. Lin HJ, Perng CL, Lee FY, Lee $\mathrm{CH}$, Lee SD. Clinical courses and predictors for rebleeding in patients with peptic ulcers and non-bleeding visible vessels: a prospective study. Gut. 1994; 35: 1389-1393.

20. Amano $Y$, Moriyama N, Suetsugu $H$, Ishimura N, Imaoka T, Komazawa $Y$, et al. Which types of non-bleeding visible vessels in gastric peptic ulcers should be treated by endoscopic hemostasis? J Gastroenterol Hepatol. 2004; 19: 13-17.

21. Ishikawa S, Inaba T, Wato M, Takashima S, Mizushige T, Izumikawa K, et al. Exposed blood vessels of more than $2 \mathrm{~mm}$ in diameter are a risk factor for rebleeding after endoscopic clipping hemostasis for hemorrhagic gastroduodenal ulcer. Dig Endosc. 2013; 25: 13-19.

22. Cipolletta L, Bianco MA, Salerno R, Prisco A, Marmo R, Cipolletta F, et al. Improved characterization of visible vessels in bleeding ulcers by using magnification endoscopy: results of a pilot study. Gastrointest Endosc. 2010; 72: 413-418. 
23. Chen VK, Wong RC. Endoscopic doppler ultrasound versus endoscopic stigmata-directed management of acute peptic ulcer hemorrhage: a multimodel cost analysis. Dig Dis Sci. 2007; 52: $149-160$.

24. Jensen DM, Kovacs TOG, Ohning GV, Ghassemi K, Machicado GA, Dulai GS, et al. Doppler endoscopic probe monitoring of blood flow improves risk stratification and outcomes of patients with severe nonvariceal upper gastrointestinal hemorrhage. Gastroenterology. 2017; 152: 1310-1318. e1311.

25. Murata A, Matsuda S. How long should patients fast after endoscopic hemostasis for nonvariceal upper gastrointestinal bleeding? Findings from a national sdministrative database. Asian Pac J Dis Manage . 2011; 5: 5-11.

26. Hebuterne $X$, Vanbiervliet G. Feeding the patients with upper gastrointestinal bleeding. Curr Opin Clin Nutr Metab Care. 2011; 14: 197-201.

27. Khoshbaten M, Ghaffarifar S, Jabbar Imani A, Shahnazi T. Effects of early oral feeding on relapse and symptoms of upper gastrointestinal bleeding in peptic ulcer disease. Dig Endosc. 2013; 25: 125-129.

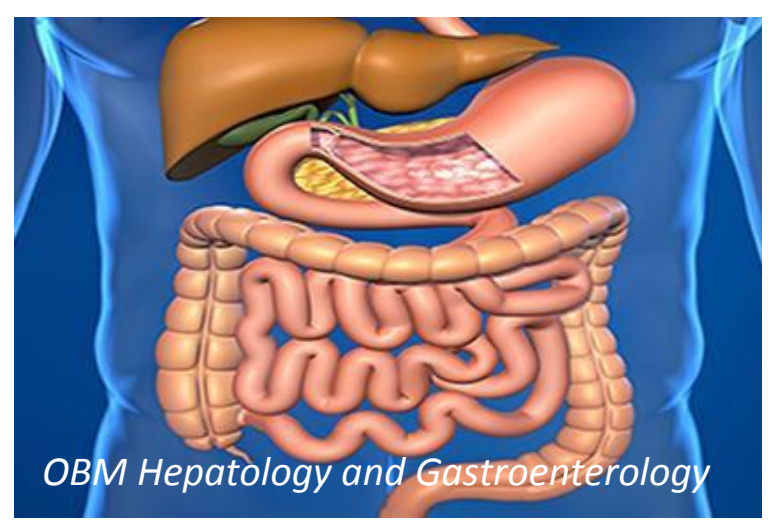

Enjoy $O B M$ Hepatology and Gastroenterology by:

1. Submitting a manuscript

2. Joining in volunteer reviewer bank

3. Joining Editorial Board

4. Guest editing a special issue

For more details, please visit: http://www.lidsen.com/journals/hg 